\title{
Directly-Modulated VCSELs for 2x2 MIMO-OFDM Radio over Fiber in WDM-PON
}

Binti Othman, Maisara; Deng, Lei; Pang, Xiaodan; Caminos, Josu; Kozuch, Wojciech Tomasz; Prince, Kamau; Jensen, Jesper Bevensee; Tafur Monroy, Idelfonso

\section{Published in:}

Proceedings of the European Conference on Optical Communication (ECOC) 2011

Publication date:

2011

Document Version

Publisher's PDF, also known as Version of record

Link back to DTU Orbit

Citation $(A P A)$ :

Binti Othman, M., Deng, L., Pang, X., Caminos, J., Kozuch, W. T., Prince, K., Jensen, J. B., \& Tafur Monroy, I. (2011). Directly-Modulated VCSELs for 2x2 MIMO-OFDM Radio over Fiber in WDM-PON. In Proceedings of the European Conference on Optical Communication (ECOC) 2011 (pp. We.10.P1.119). Optical Society of America. http://www.ecoc2011.org/

\section{General rights}

Copyright and moral rights for the publications made accessible in the public portal are retained by the authors and/or other copyright owners and it is a condition of accessing publications that users recognise and abide by the legal requirements associated with these rights.

- Users may download and print one copy of any publication from the public portal for the purpose of private study or research.

- You may not further distribute the material or use it for any profit-making activity or commercial gain

- You may freely distribute the URL identifying the publication in the public portal 


\title{
Directly-Modulated VCSELs for 2x2 MIMO-OFDM Radio over Fiber in WDM-PON
}

\author{
M. B. Othman ${ }^{1,2}$, Lei Deng ${ }^{1}$, Xiaodan Pang ${ }^{1}$, J. Caminos ${ }^{1}$, W. Kozuch ${ }^{1}$, K. Prince ${ }^{1}$, J. Bevensee Jensen ${ }^{1}$, \\ I. Tafur Monroy ${ }^{1}$ \\ ${ }^{I}$ DTUFotonik, Department of Photonics Engineering, Technical University of Denmark, Ørsteds Plads 343, DK-2800 Kgs. Lyngby, Denmark \\ ${ }^{2}$ Department of Communication Engineering, Faculty of Electrical and Electronic Engineering, UTHM, 86400 Parit Raja, Johor, Malaysia. \\ mabio@fotonik.dtu.dk, kpri@fotonik.dtu.dk,jebe@fotonik.dtu.dk, idtm@fotonik.dtu.dk
}

\begin{abstract}
We demonstrate directly- modulated VCSELs supporting 2x2 MIMO-OFDM 5.6-GHz radio over fiber signaling over 20-km WDM-PON. Error-free signal demodulation of 64-subcarrier 4-QAM signals modulated at $198.5-\mathrm{Mb} / \mathrm{s}$ is achieved after fiber and $2-\mathrm{m}$ indoor wireless transmission.

OCIS codes: (060.0060) Fiber optics and optical communications; Radio frequency photonics (060.5625)
\end{abstract}

\section{Introduction}

Radio over fiber (RoF) technology is a promising solution for integrating wireless and fixed-line communication networks. Multiple input multiple output (MIMO) technology has improved transmission distances and increased the data rates supported by modern wireless networks without any additional power or bandwidth expenditure [1]. Such multiple antenna techniques however present a challenge for RoF systems, which have to ensure clean transmission of multiple signals between elements of the antenna array, and must mitigate signal path impairments which introduce crosstalk, attenuation and multipath fading [2]. Sophisticated receiver algorithms may be implemented to overcome these path-dependent effects. Orthogonal frequency division multiplexing (OFDM) has emerged as the leading modulation technique in the wireless domain. The combination of OFDM with MIMO technique provides an attractive solution because of the very simple implementation, and potentially high spectral efficiency [3]. Wavelength division multiplexed passive optical network (WDM-PON) systems supporting higher bandwidth can transparently deliver radio frequency signaling required to support hybrid fixed and wireless access networking systems. WDM-PON technology is therefore expected to further improve the throughput in the wireless service area covered by RoF-MIMO antennas [4]. Previously, distributed feedback (DFB) laser diodes have been suggested for use in WDM-PON but have failed to attract industry attention because of the high cost [5]. Directly modulated vertical-cavity surface-emitting lasers (VCSELs) have emerged as an attractive solution for WDM-PON due to the cost effective production, low power consumption [6], capability for chip integration with the low threshold and driving current operation [7].

Previous simulation work has been done towards integrating MIMO-OFDM technology with RoF [2], and integrating dense wavelength division multiplexing (DWDM) with MIMO-OFDM [8]. The experimental work in [9] demonstrates the MIMO RoF concepts, but that analysis implemented separate fibers for each remote access unit (RAU). This paper presents, to the best of our knowledge, the first experimental demonstration of a low cost allVCSEL 2x2 MIMO OFDM over WDM-PON system. We have successfully demonstrated wireless MIMO transmission with 4-QAM OFDM over 2x2 MIMO array.

\section{Experiment setup}

The experimental setup of the system is illustrated in Fig.1. In the central office (CO), two different real valued 64-subcarrier 4-QAM OFDM baseband signals with $198.5 \mathrm{Mb} / \mathrm{s}$ net data rate and $312 \mathrm{MHz}$ bandwidth are generated by an arbitrary waveform generator (ArbWaveGen). The OFDM symbols are arranged in frames of 10 symbols. The first 3 symbols implement the training sequence; and 10\% cyclic prefix is added. A dual channel baseband MIMOOFDM signal is generated in the ArbWaveGen, which is then up-converted to a $5.65 \mathrm{GHz}$ radio frequency (RF) carrier; the signal in one arm is up-converted using the vector signal generator (VSG) and the other arm implements RF up-conversion using a mixer. Different training sequences are used for each sub-element of the MIMO-OFDM signal; this enables estimation of the MIMO wireless channel response. The electrical MIMO-OFDM signals directly modulate two VCSELs operating at different bias levels to generate different wavelengths of $1535.29 \mathrm{~nm}$ and $1536.09 \mathrm{~nm}$. Both WDM optical signals are combined using $3 \mathrm{~dB}$ coupler; they propagate through $20 \mathrm{~km}$ non- 


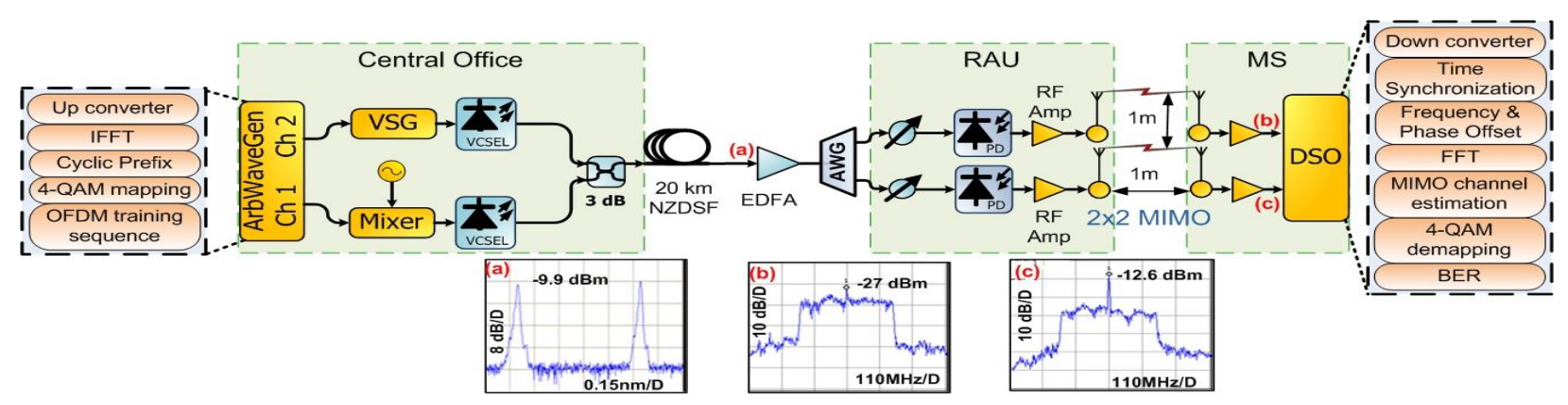

Fig. 1: Experiment setup for all-VCSELs for WDM-PON with 4-QAM OFDM signals over $20 \mathrm{~km}$ NZDSF and 2x2 wireless MIMO.

zero dispersion shifted fiber (NZDSF). The optical spectrum of the CO transmitter output is shown in Fig 1(a). After $20 \mathrm{~km}$ NZDSF transmission, the downstream WDM signals are divided using an arrayed waveguide grating (AWG). After the photodetector, RF amplifiers boost the signal with $20 \mathrm{~dB}$ gain, at the (RAU) antenna. The wireless signals propagate through 1 meter distance. Elements of the $2 \times 2$ antenna array implemented at both RAU and mobile station (MS) are vertically spaced by 1 meter; vertical polarization is implemented for the wireless link. At the MS receiver, the signals are captured by two antennas and amplified with $20 \mathrm{~dB}$ gain electrical amplifier. The RF OFDM signals are sampled by a digital sampling scope (DSO), with $20 \mathrm{Gs} / \mathrm{s}$ sampling rate. The electrical MIMO-OFDM spectrum is shown in Fig. 1 (b) for the VSG and (c) for the mixer. A digital signal processing (DSP) enabled receiver at the MS uses the different training sequences implemented on sub-elements of the MIMO-OFDM wireless transmission to identify the MIMO signals radiated from each antenna element, and demodulates the OFDM signals. Signal down-conversion, time synchronization, frequency and phase offset removal and fast Fourier transform (FFT) processing are implemented in DSP. Compensation for crosstalk and multipath fading is done using a minimum-mean-square-error MMSE algorithm. The bit error rate (BER) is calculated after symbol demapping. Transmission quality was assessed using BER sensitivity to received optical power metric. We consider a BER of $10^{-3}$, since forward error correction (FEC) techniques may be applied to obtain error free transmission.

\section{Results}

Figure 2 presents BER results obtained as the MIMO signal propagates through the system; we distinguish between signal elements upconverted using mixer (solid symbols) and VSG (hollow symbols). Fig. 2(a) shows variation of BER with optical power for both signal paths, for optical back to back (B2B) (circle) and after fiber transmission (square). From these results, we observe that the mixer-generated signal requires $3 \mathrm{~dB}$ more optical power to achieve BER $10^{-3}$ than the VSG-generated signal. For B2B, the FEC threshold is achieved when PD input power is approximately $-12.3 \mathrm{dBm}$ and $-15.2 \mathrm{dBm}$ for VSG and mixer, respectively. After $20 \mathrm{~km}$ of fiber, the FEC limit at achieved with received optical power of approximately $-11 \mathrm{dBm}$ for VSG and $-13.8 \mathrm{dBm}$ for mixer. After fiber transmission, $1.5 \mathrm{~dB}$ power penalty is observed for both mixer and VSG-generated signal streams. Fig. 2(b) illustrates the BER results obtained with wireless transmission, for B2B (circle) and after fiber (square); corresponding post-PD electrical constellations are also shown in the inset. With wireless transmission, $2 \mathrm{~dB}$ additional power is required at the PD input was observed for both B2B and fiber transmission of both mixer and VSG-generated signals. Less than $2 \mathrm{~dB}$ power penalty is observed for both signal elements, for both B2B and after fiber. After fiber transmission, system performance is also affected by varying the separation between RAU and MS. Fig. 2(c) presents BER variation with received optical power (ROP) at different wireless distances between RAU and MS; results are assessed at $1 \mathrm{~m}$ (circle), $2 \mathrm{~m}$ (square) and $3 \mathrm{~m}$ (triangle). The insets show received constellation diagrams observed at the MS; clear 4-QAM OFDM constellations are obtained. Increasing power penalty is observed as wireless transmission distance is increased. For a fixed transmit power, increased wireless transmission distance also increases path attenuation. This reduced the received signal to noise ratio (SNR) and increased BER. This agrees well with experimental observations. Even though we are facing this problem as well as the interference effect and multipath fading, we could achieve error free transmission after 2 meters of wireless transmission. This can be clearly seen from the 4-QAM OFDM constellation diagram in Fig. 2(c). We observe that increasing the distance between RAU and MS reduces the performance difference observed between the two MIMO signals; this difference is within $0.5 \mathrm{~dB}$ after $3 \mathrm{~m}$ wireless transmission. After fiber transmission, the effect of antenna separation on performance is assessed by varying the spacing between the elements of the RAU and MS antenna arrays, while preserving $1 \mathrm{~m}$ transmission distance between RAU and MS. The results obtained with antenna spacing of $0.5 \mathrm{~m}$ (square), $1 \mathrm{~m}$ (circle) and $1.5 \mathrm{~m}$ (diamond) are presented in Fig. 2(d). We observe similar performance without any penalty for all separations for both channels in Fig. 2(d). This suggests that $0.5 \mathrm{~m}$ antenna separation is sufficient for 
the system to implement MIMO transmissions. Furthermore, the MIMO-OFDM system demonstrates good tolerance to path-dependent effects for the demonstrated 2x2 MIMO array. 4-QAM constellation diagrams for $0.5 \mathrm{~m}$ antenna separation are shown for both channels in the Fig 2(d); these obtained at BER $10^{-3}$.

(a)

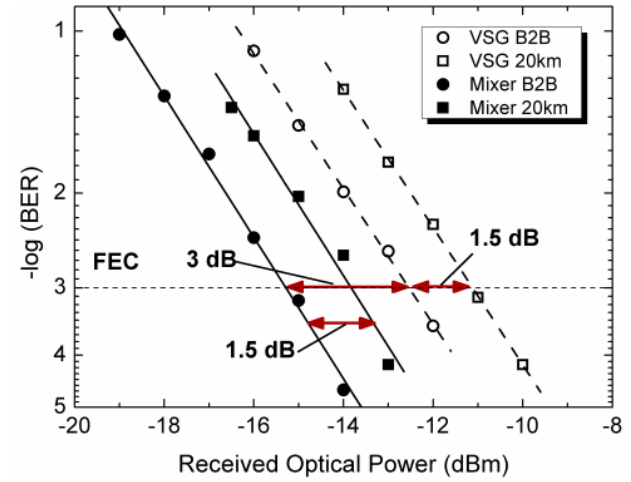

(c)

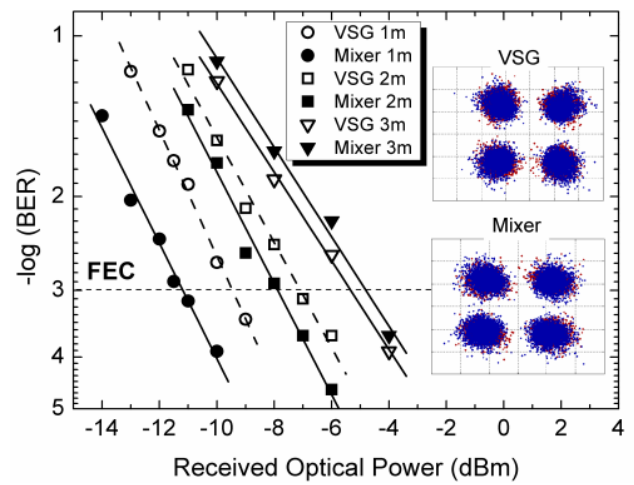

(b)

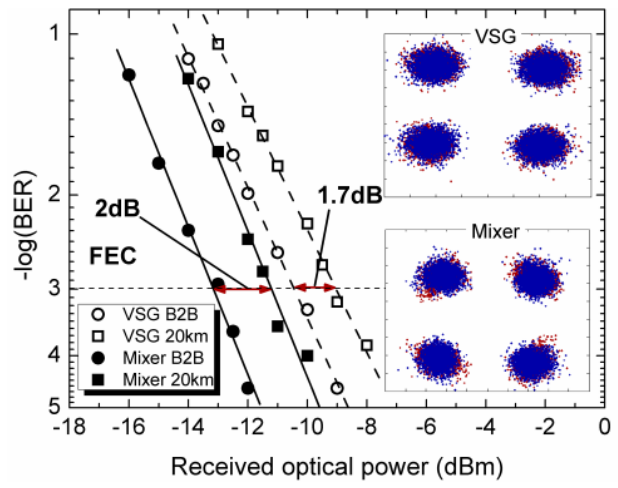

(d)

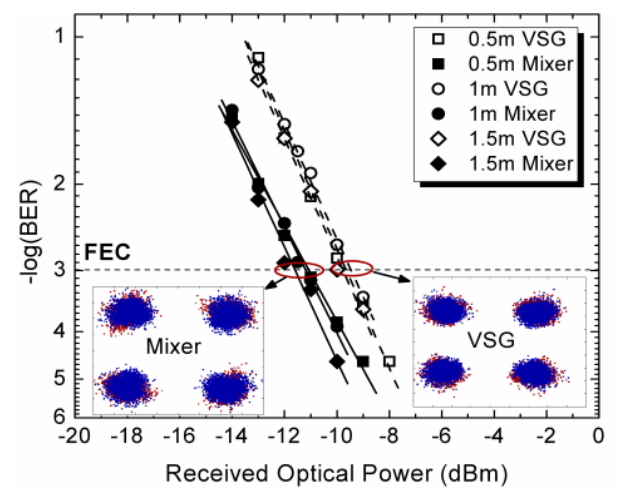

Figure 2: Showing variation of (a) BER with received optical power (ROP) for optical back-to-back (B2B) and after 20 km NZDSF: (b) BER with ROP for 2x2 MIMO wireless transmission at B2B and after optical fiber: (c) BER with ROP after fiber transmission, at various distances between RAU and MS: and (d) BER with ROP after fiber transmission, for different antenna separation, with fixed 1 meter distance between RAU and MS. MIMO signal elements which are upconverted using mixer (solid symbols) and VSG (hollow symbols) are identified. Insets show constellation obtained at FEC limit $\left(\mathrm{BER}=10^{-3}\right)$.

\section{Conclusions}

We have presented the first known demonstration of MIMO-OFDM signal distribution in a WDM-PON system using all-VCSELs optical sources with wireless MIMO transmission; this provides potentially a cost effective solution for future access networks. MIMO-OFDM algorithms also effectively compensate for impairments in wireless link. We also investigate the effects of various wireless transmission path length and antenna separation to see the robustness of the MIMO-OFDM algorithm. We report error free transmission after $20 \mathrm{~km}$ NZDSF and 2 meter $2 \times 2$ wireless MIMO-OFDM at $198.5 \mathrm{Mb} / \mathrm{s}$ with $5.65 \mathrm{GHz}$ radio over fiber signaling transmission for WDMPON system. No penalty was observed for varying antenna separation of the sub-elements of the MIMO-OFDM signal with $1 \mathrm{~m}$ separation between RAU and MS. We believe this work can be a potentially attractive candidate for last mile home network.

\section{References}

[1] M. Sauer, et. al, "Radio over fiber for picocellular network architectures" JLT, 25(11) (2007).

[2] I. Harjula et.al, "Practical issues in the combining of MIMO techniques and RoF in OFDM/A systems" Proc. of the 7th WSEAS, 244-248, (2008).

[3] W.Shieh at. al, OFDM for Optical Communication, Chapter $1 \&$ 12, (Elsevier, 2010) .

[4] K.Tsukamoto, et.al, "Convergence of WDM Access and Ubiquitous Antenna Architecture for Broadband Wireless Services" PIERS Online, 6(4) (2010).

[5] Wen-Shing Tsai et. al, "Bidirectional dense wavelength-division multiplexing passive optical network based on injection-locked vertical cavity surface-emitting lasers and a data comparator" Optical Engineering, 45(9), (2006).

[6] E. Kapon et. al, "Long-wavelength VCSELs: Power-efficient answer" Nature Photonics 3, 27 - 29 (2009).

[7] R. Rodes et.al, "All-VCSEL based digital coherent detection link for multi Gbit/s WDM passive optical networks" Opt. Exp., 18(24) (2010).

[8] S. Nema, et.al, "Convergence Integrated DWDM and MIMO-OFDM System for 4G High Capacity Mobile Communication" Signal

Processing an International Journal, 3(5),(2010).

[9] A. Kobyakov, et.al, "Effect of Optical Loss and Antenna Separation in 2x2 MIMO Fiber-Radio Systems" IEEE T. Ant \& Prop, 58(1),(2010). 